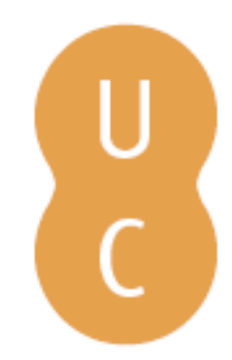

\title{
nommalina
}

\section{El proyecto FVNDVS de la villa romana de Noheda: planteamientos metodológicos y primeros resultados}

\author{
Autor(es): $\quad$ Valero Tévar, Miguel Ángel \\ Publicado por: Imprensa da Universidade de Coimbra \\ URL \\ persistente: $\quad$ URI:http://hdl.handle.net/10316.2/42109 \\ DOI: $\quad$ DOI:https://doi.org/10.14195/978-989-26-1353-6_3 \\ Accessed : $\quad$ 26-Apr-2023 14:34:28
}

A navegação consulta e descarregamento dos títulos inseridos nas Bibliotecas Digitais UC Digitalis, UC Pombalina e UC Impactum, pressupõem a aceitação plena e sem reservas dos Termos e Condições de Uso destas Bibliotecas Digitais, disponíveis em https://digitalis.uc.pt/pt-pt/termos.

Conforme exposto nos referidos Termos e Condições de Uso, o descarregamento de títulos de acesso restrito requer uma licença válida de autorização devendo o utilizador aceder ao(s) documento(s) a partir de um endereço de IP da instituição detentora da supramencionada licença.

Ao utilizador é apenas permitido o descarregamento para uso pessoal, pelo que o emprego do(s) título(s) descarregado(s) para outro fim, designadamente comercial, carece de autorização do respetivo autor ou editor da obra.

Na medida em que todas as obras da UC Digitalis se encontram protegidas pelo Código do Direito de Autor e Direitos Conexos e demais legislação aplicável, toda a cópia, parcial ou total, deste documento, nos casos em que é legalmente admitida, deverá conter ou fazer-se acompanhar por este aviso.

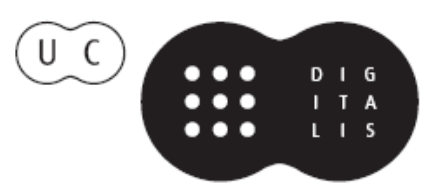




\section{Arqueologia \\ da transição:}

entre o mundo romano

e a Idade Média

Cláudia Teixeira, André Carneiro (coords.)

IMPRENSA DA UNIVERSIDADE DE COIMBRA

ANNABLUME 


\title{
El proyecto FVNDVS de la Villa romana de Noheda: PLANTEAMIENTOS METODOLÓGICOS Y PRIMEROS RESULTADOS (The FVNDVS project and the roman villa of Noheda: methodological issues and first results)
}

\author{
Miguel Ángel Valero TÉvar (mvalero@cuenca.uned.es) \\ UNED Centro Asociado de Cuenca
}

\begin{abstract}
Resumo - As escavações arqueológicas que nos últimos anos foram realizadas na villa romana de Noheda permitiram divulgar o seu excepcional mosaico figurativo e analisar os aspectos micro-espaciais relacionados do sítio nos seus diversos espaços e nas suas sequências de ocupação. Todavia, o estudo não estaria completo sem analisar de modo macro-espacial o território envolvente, de modo a compreender a sua verdadeira dimensão histórica e contextual. Este artigo apresenta a metodologia e primeiros resultados desta análise.

Palavras-chave - Villa tardo-romana; mosaicos: fundus; povoamento romano; paisagem.
\end{abstract}

Aвstract - Archaeological interventions developed in recent years in the Roman villa of Noheda have allowed, not only to publicize its exceptional figurative mosaic but also a quite accurate approximation to the microspatial aspects of the enclave and its occupational sequence. However a study of this magnitude would not be complete without approaching the research at macrospatial level of the territory where the complex is inserted, in order to serve to give it its true historical dimension. This article involves exposure of the methodology and the first results obtained with it.

KEYwords - Late Roman Villa, mosaics, fundus, roman population, lansdcape.

\subsection{InTRODUCCIÓN}

La presente contribución supone la presentación del proyecto de análisis territorial fundus de la villa romana de Noheda, la exposición de la metodología que se está llevando a cabo y los primeros datos extraídos de la aplicación de la misma.

Este trabajo surge de la necesidad de contribuir al estudio integral del yacimiento, ya que, si bien es justo reconocer que hasta el momento ha sido el mosaico figurado localizado en el triclinium de la villa la evidencia más notoria del mismo por la cual es conocido (Valero 2009: 54; 2010b: 6; 2011: 91ss; 2013a: 307ss; Valero e.p.; Valero y Gómez 2013: 87ss), consideramos que la investigación sobre el enclave debe plantearse de manera integral, es decir, sin olvidar el tapiz musivario, pero otorgando la misma relevancia al resto de los aspectos conformadores de la villa. En esta línea, ya se han efectuados algunos estudios analizando arquitectónicamente diversas estancias, la cronologia del complejo, la 
evolución de las fases constructivas, las técnicas edilicias empleadas y el proceso de destrucción (Valero 2014b: 233). Del mismo modo también se han abordado análisis sobre los elementos que ornamentaban la pars urbana del complejo (Valero, Gutiérrez y Rodà e.p.), el estudio de captación de recursos hídrocos con los que se abastecía el complejo rural (Mejías et alii 2013: 17; Martínez et alii 2014: 2), o los primeros resultados sobre los programas de prevención y conservación efectuados en el tapiz musivario (Valero et alii 2014: 1667). Por ello el analisis del territorio susceptible de conformar el fundus de la quinta, y sus adaptaciones y/o transformaciones con motivo de la inserción del espacio en el ámbito de explotación de la villa, suponen un dato de especial importancia de cara al conocimiento exhaustivo del complejo rural.

Para el estudio de aprovechamiento territorial y ordenación de la población del fundus de la villa de Noheda, nos hemos valido de las directrices esgrimidas por la llamada Arqueología del Paisaje, que otorga especial interés a éste, considerándolo no solamente como un espacio físico, si no que en su conjunto forma un marco ambiental en el que el hombre está obligado a vivir, incidiendo en mayor o menor medida sobre él (Criado et alii 1991: 28). De este modo, estudiando el paisaje se puede comprender como una sociedad determinada se asienta en él, adaptándose al mismo, y/o modelándolo en distinto grado. Uno de los aspectos más interesantes de este tipo de investigación, es el que permite apreciar las diferencias en la manera de ocupar y explotar un territorio entre las distintas sociedades (Gómez et alii 2005: 29).

Nuestra propuesta continua el camino marcado en otras zonas y que tan buenos resultados han ofrecido, con aportaciones metodológicas que permiten abordar el estudio integral de un paisaje determinado, poniendo de manifiesto la necesidad de valorar adecuadamente el patrimonio arqueológico rural de cara a la correcta comprensión del fenómeno de la transformación sufrido en la época romana (Dyson y Alden 1978: 21; Harke 1981: 57; Davidson y Bailey 1984: 26; Filloy y Gil 1984: 9; Pons 1984; 29; Duran y Padilla 1990; Carrillo e Hidalgo 1991: 38; Criado et alii 1991; Orfila y Cardell 1991-92: 41; Villanueva 1991: 319; Escacena y Padilla 1992; Orejas 1995/96: 61; eadem 1996; Moreno 1997: 205; Palet et alii 1998: 153; Pérez y Borreda 1998: 133; Amores et alii 2001: 414; Henares 2001: 607; García Vargas et alii 2002: 313; González 2002; Vargas y Romo 2002: 149; Sáez et alii 2002; Gisbert 2003: 121; Ariño et alii 2004; Fernández et alii 2004: 216; Gómez et alii 2005: 28; Orejas et alii 2005: 42; Pérez 2006; Sáez et alii 2006 141; Rodríguez 2007: 133; Moscardó 2008: 177; Moreno y Quixal 2009: 110; Gutiérrez 2010: 13; Deprez et alii 2011: 36: Gómez et alii 2011; López-Romero 2011: 83; Rubio 2011: 145).

La riqueza arqueológica del territorio circundante de la villa es un hecho demostrado, encontrando evidencias antrópicas en la zona de prácticamente todas la etapas cronoculturales. De este modo, el Abrigo de Buendía con diversas ocupaciones en el Paleolítico Superior, supone la primera prueba documentada 
hasta el momento de hábitat en la zona (Torre et alii 2007: 537). Mayor información se tiene de la Edad del Bronce, en la mayoría de los casos basado en análisis territoriales (Martínez González 1988; Martínez Navarrete 1988a; eadem 1988b; Díaz-Andreu 1990; eadem 1994; Valero 1996; idem 2012b), si bien también se cuenta con publicaciones sobre yacimientos específicos (Valiente 1974: 134; Martínez González y Martínez Navarrete 1988: 218). Hasta el momento, resultan más escuetos los datos acerca de la Edad del Hierro (Díaz-Andreu y Sandoval 1991/92: 226; Valero 1999a: 10; idem 1999b: 306; ter 2012a: 47-60; Domingo et alii 2007: 220), si bien nuevos proyectos, aun en desarrollo, auguran avances en el conocimiento de esta etapa (Valero 2013b: 236). Pero sin duda será el estudio sobre la época romana el que ha cobrado mayor intensidad (Palomero 1987; Zarzalejos y Morillo 1994: 166; Solías 1997: 220; Castelo et alii 2000: Guisado y Bernárdez 2002: 276; idem 2003: 246; Busquier 2010: 3.02; Valero 2010b: 203), condicionado en gran medida por la relevancia de la ciudad de Ercávica, donde tras los primeros estudios (Osuna 1976; idem 1997: 173; Lorrio 2001), ha primado el análisis del fenómeno urbano (Rubio 2004: 217; 2006: 187; 2008: 136; 2010: 1031; 2013: 170; Rubio y Valero 2007: 436) sin olvidar su amplio territorium (Valero 2013b: 217).

Pese a la demostrada antropización de la comarca, ésta no ha suscitado excesivo interés, no acometiéndose investigaciones que abordasen de manera diacrónica la ocupación de este territorio hasta los últimos años (Valero 2013b: 211).

Por ello será en el entorno inmediato de la villa romana de Noheda donde, en aras del arriba citado conocimiento global del enclave y profundizando en esta línea de investigaciones sobre el territorio, intentaremos ahondar en la realidad de explotación parcelaria de época romana, que arranca en el momento de uso de la primera villa documentada, continúa en la fase tardoantigua, coincidiendo con la etapa álgida del complejo rural y se desarrolla de manera ininterrumpida hasta nuestros días con las consiguientes transformaciones paisajísticas.

\subsection{LA VILLA Y SUS MOSAICOS}

El yacimiento de la villa romana de Noheda es conocido desde antiguo (Larrañaga 1966: 438; Abascal 1982: 68; Palomero 1985: 169), si bien es tan solo en fechas recientes cuando ha comenzado a ser difundido de manera rigurosa (Valero 2009: 54; 2010a: 6; 2011: 91ss; 2013a: 307ss; 2014: 521; Valero y Gómez, 2013: 87ss; Valero et alii 2014: 1667), junto con algunos enfoques divergentes en cuanto a la lectura de sus mosaicos (Fernández 2010: 136; Ucatescu 2013: 297-299).

Se ubica en la parte central de la Península Ibérica, próxima de las ciudades de Segóbriga (a $58 \mathrm{Km}$.), Ercávica (a 44,5 Km.) y Valeria a (43,5km.), situándose a $17 \mathrm{~km}$. al norte de la ciudad de Cuenca. La villa se localiza a escasos $500 \mathrm{~m}$. al 
noroeste de la localidad de la cual toma su nombre, siendo ésta pedanía de Villar de Domingo García. (Fig. 1)

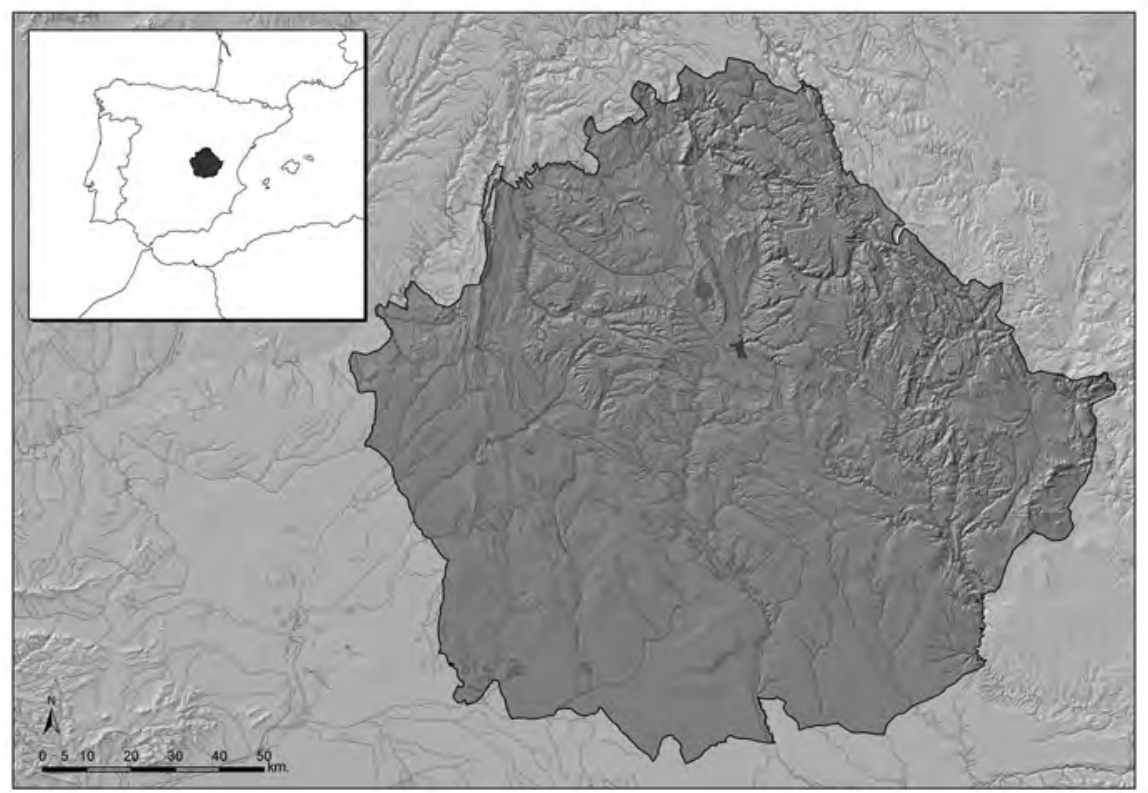

Figura 1 - Plano de localización de Noheda.

El complejo arqueológico fue declarado Bien de Interés Cultural en 2012, principalmente por los mosaicos descubiertos en él, si bien no es solo la etapa tardoantigua la que cuenta con evidencias antrópicas, aunque es justo reconocer que es, hasta el momento, la mejor documentada. Las investigaciones realizadas en los últimos años han puesto de manifiesto que bajo la villa romana tardoantigua, resulta probada la existencia de estructuras arqueológicas pertenecientes al Alto Imperio, en un estado de conservación bueno pese a haber sido cantera de las construcciones suprapuestas (Valero 2015: passim).

Dichas construcciones coinciden cronológicamente con el proceso de eclosión y auge de las grandes villae documentadas en la parte occidental de Imperio (Vera 1992-1993: 299; Volpe 1996: 210; Sfameni 2006: 19-21; Chavarría 2006: 19; eadem 2007: 53ss; Pensabene 2010-2011: 171-174; Hidalgo 2014a: 229). De este modo, hasta el momento son tres las áreas exhumadas de la villa, por un lado algunas estructuras que a tenor del espacio excavado parecen pertenecer a la pars rustica. De esta manera, el complejo contaría con los edificios necesarios que le otorgarían esa vocación agrícola que resulta inherente al concepto de villa rústica (Richmond 1970:51; McKay 1975:100-108; Percival 1976: 13; Johnston 1983: 3-8; Balmelle 2001: 16; Gros 2001: 265: Mulvin 2002: 3; 
Chavarría 2005, 523-526; eadem 2007: 32; 54; Arce 2006: 14; idem 2009: 136; ter 2012: 27; Sfameni 2006: 110) a lo largo de toda la época romana ${ }^{1}$.

Por otro lado, y habiendo centrado los esfuerzos en estas zonas, se ha excavado una parte de la pars urbana, compuestas por el balneum y determinadas estancias del edificio residencial. Éste último se conforma con varias dependencias de holgadas dimensiones entre las que destaca la denominada Sala Triabsidada, no sólo por su imponente superficie - de 290,64 $\mathrm{m}^{2}$ - y sus extraordinarios pavimentos, sino también por su compleja articulación arquitectónica donde la multiplicidad de ábsides es una constante, a lo que habría que añadir una cuidada decoración parietal compuesta por un zócalo de placas de mármol y un colorido alzado de pintura mural.

La mencionada morfología cuadrangular con exedras en tres de sus lados, permiten adscribirla al tipo de salas tríforas que se hacen frecuentes en los más lujosos conjuntos residenciales bajoimperiales (Balmelle 2001: 327-328; Romizzi 2001: 19; Sfameni 2006: 166). Se trata de dependencias de articulación trichora que comúnmente vienen interpretándose como triclinia (Hidalgo 1998: 283; 2014a: 233; 2014b: 538; Dunbabin 2003: 198; Mar y Verde 2008: 78; Arce 2010: 40), adaptando así las formas arquitectónicas a las nuevas tendencias en la organización espacial de los comensales de banquetes, con lechos dispuestos en semicírculo, los stibadia (Rossiter 1991: 199; Volpe 2006: 321).

Es en esta estancia donde se halla el excepcional mosaico figurativo que cuenta con unas dimensiones conservadas de $231,62 \mathrm{~m}^{2}$, realizado en su mayor parte con opus vermiculatum de una variadísima gama cromática, utilizándose para determinados colores piezas de pasta vítrea en multitud de tonos e incluso doradas.

La composición ornamental de este pavimento está formada por un lado, de una amplia zona central dividida en seis paneles con escenas de temática mitológica y alegórica, que presentan un carácter unitario y donde se abigarran profusamente las figuras, aglutinándose en grupos escénicos. Este conjunto figurativo, cuya forma rectangular se reparte el espacio principal de la sala, se extiende entre el centrado estanque monumental y el enmarque realizado con

${ }^{1}$ No es necesario recordar que la agricultura era considerada por los romanos como un método adecuado de autoabastecerse, pero sobre todo de enriquecerse de manera honesta, frente a la acumulación de riqueza mediante la guerra, el comercio, la usura y los cargos públicos (Col.I.1). De hecho, son varios los autores (Catón, Varrón, Columela y Paladio) que han dedicado esfuerzos en transmitir mediante tratados, libros y otras fuentes, las bondades de la vida en el campo, así como su mejor y más adecuada manera de explotación del mismo. Estos autores que han instruido acerca del mundo rural, son los denominados scriptores rei rusticae. Pero los datos aportados por cada uno de los autores, han de ser tomados teniendo en cuenta la época en la que se escriben, qué ámbito describen, normalmente la Península Itálica y para quién van dirigidos, las clases acomodadas que viven en la ciudad y cuentan con posesiones en el campo. Por tanto como se ha indicado (Palahí y Nolla 2010,12) la historia de las villae, es la historia de una ideología y de los intereses económicos de las clases dirigentes y de las circunstancias políticas y económicas de cada una de las etapas por las que pasó el Imperio Romano. 
una amplia orla vegetal de roleos de hojas de acanto, más elaborados en la parte central de las tiras, en los espacios coincidentes con el acceso a las tres exedras de la estancia, que contarían con decoración geométrica, a tenor de lo observado en las dos conservadas.

Los cuadros figurativos fueron estructurados en seis franjas rectangulares, denominadas, a efectos de descripción y estudio, por orden de visionado del visitante a la sala: A, B, C, D, E y F. (Fig. 2)

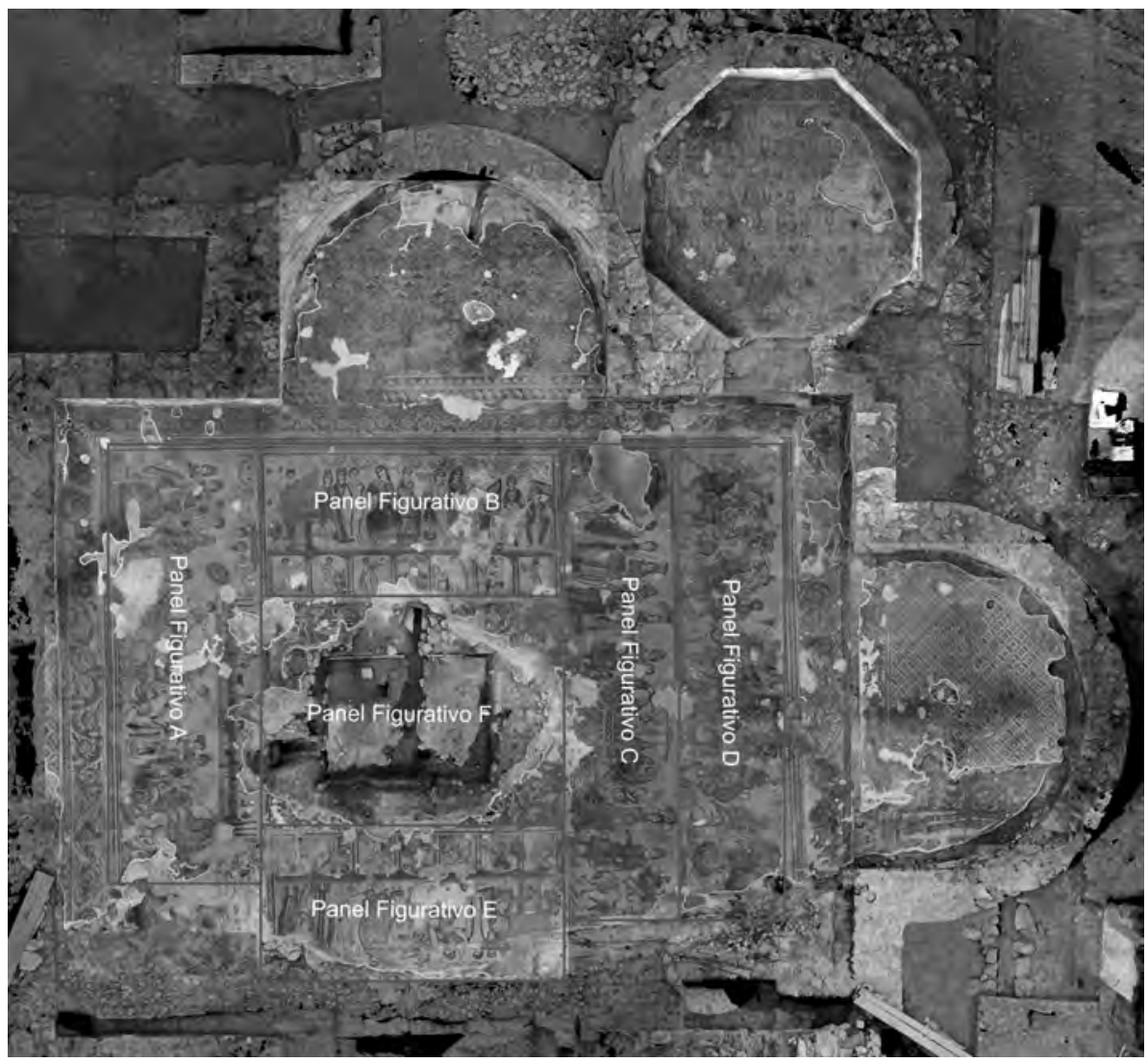

Figura 2 - Subdivisión en paneles figurativos del mosaico del triclinium de Noheda (imagen de M.Á. Valero sobre la foto del mosaico de José Latova).

Así la escena A representa la contienda mantenida entre el rey de Olimpia, Enómao y el príncipe anatolio, Pélope por Hipodamia, la hija de aquel. Se divide en tres grupos escénicos, el primero de ellos compacto, de cinco personajes en torno al monarca entronizado, el siguiente refleja en primer lugar, el violento naufragium sufrido por la cuadriga del soberano, continuando con la plasmación de Pélope vencedor descendiendo de la barquilla del carro mientras es abrazado 
por Hipodamia y recibe de ésta la palma de la victoria. Completaría la escena un tercer del que solo quedan dos personajes que asisten a los corceles, habiendo sido destruido por la acción del arado. Sobre el cuadro escénico principal, otro ubicado en la parte superior de menores dimensiones en la que se aprecia un circo - alusivo a la carrera de cuadrigas - donde se plasma la cavea, la arena, la spina, las metae, los ovaria, el phala, así como varias esculturas de dioses y animales que ornamentarían el edificio.

El mito de Pélope, Enómao e Hipodamía, si bien contó con gran aceptación en la tradición mitológica (Triantis 1992: 693; 1994: 19; 282; Alvar 2000: 865; Schwab 2009: 134; Humbert 2010: 166), no son muchas las representaciones del mismo.

Una de las escenas más espectaculares del mito se encuentra en las esculturas de bulto redondo que ornamentaban el frontón oriental del Templo de Zeus en Olimpia (Frontinos 1989: 60). Esta leyenda también es representada en algunos sarcófagos del siglo III (Balty 1989: 500; Blázquez, López y San Nicolás 2004: 292). Así como en el arte vascular donde destaca el caso de vaso de figuras rojas custodiado en el Museo de Atenas (Sparkes 1996:125).

Sin embargo en mosaicos, no son abundantes las escenas alusivas a esta historia tradicional griega. El más elocuente es el mosaico ubicado en el Museo de Damasco de procedencia desconocida (Balty 1989: 498). Además, ya en territorio hispano, en la villa del Arellano, se ha documentado un dextrarum iunctio que tradicionalmente ha sido interpretado como correspondiente a los esponsales de Attis con la hija del rey de Pessinonte (Mezquíriz 2003: 234). No obstante, las similitudes en la disposición y vestimenta de los personajes del yacimiento navarro resultan a los que aparecen en la Sala Triabsidada de la villa de Noheda, son más que evidentes.

Si escasas son las representaciones musivarias del mito, no ocurre lo mismo con las escenas en que aparecen cuadrigas y los mismos circos (López 1994: 343ss). Quizás el más famoso de ellos sea el plasmado en la palestra de la villa del Casalle de Piazza Armerina (Catullo 1999: 35), pero también en la zona norteafricana se cuenta con varios ejemplos (Ennaifer 1994: 255), así como en territorio griego (Lemaître 2009: 75ss).

Ya en territorio hispano son varios los ejemplos musivos con representaciones circenses, lo que unido a los documentos epigráficos y los testimonios arqueológicos ponen de manifiesto un considerable gusto por los ludi circenses en la Península Ibérica.

De este modo, por citar algunos de los más significativos, indicaremos el denominado mosaico del circo de Barcelona (Balil 1962 257ss; Blázquez 2003: 195ss), o la representación circense que se localiza en el mosaico de Can Pau Birol en Bell-1loc (Nolla et alii 1993: 34ss). No podemos olvidar un mosaico con escenas del circo muy fragmentario, procedente del Cortijo de Paterna en Paradas, Sevilla, datado a finales del siglo IV o inicios del V (López 1994: 350), o el 
que existió y conocemos mediante un dibujo (Laborde 1806) del denominado mosaico del Circo o de las Musas. En esta misma zona bética, el circo también aparece en un mosaico excavado solamente de manera parcial en 2010, donde se aprecian las carceres, un extremo de la spina, una victoria alada y dos personajes de pie junto a varias inscripciones (León et alii 2010: 149).

La escena B, ubicada en la zona norte de la sala, se divide igualmente en dos subescenas, en la principal, representa una compañía teatral en la que se suceden todos los componentes de la pantomima, bajo ésta se sitúa otra de menores dimensiones cuyos personajes, alusivos a los ludi, se encuentran enmarcados entre dobles columnas techadas por una sucesión de dinteles rectos y arcos escarzanos.

La escena $\mathrm{C}$ se localiza en la parte oriental de la estancia, dividiéndose igualmente en grupos escénicos. El primero de ellos compuesto por un conjunto de cinco personajes, tres femeninos frente a uno masculino vestido con túnica y sentado sobre una roca a la sombra de un árbol, entre ellos Eros. Representa el juicio de Paris, mito de larga tradición que gozó de una gran aceptación en las fuentes clásicas, siendo representado asiduamente en la pintura vascular (Clairmont 1951: 60), en frescos parietales, en relieves, en espejos, o piedras preciosas e incluso monedas. Por el contrario, su plasmación en pavimentos musivos resulta escasa (Levi 1947: 16; Morricone 1950: 219; Dunbabin 1978: 254; Mondelo y Torres 1985: 148; Buenacasa 2006: 26; Blázquez 2014 : 109-110; López 2014: 118; Choclán e.p.).

El siguiente conjunto escénico, se desarrolla en torno a un barco con cuatro marineros a bordo, dos de ellos que se afanan en izar las velas y desatracar la nave, mientras los otros dos tripulantes centran sus esfuerzos en atar amarras, simbolizando unos la partida y otros la llegada a puerto. Al navío, mediante una rampa situada en la popa, accede Paris mientras agarra la mano de la raptada Helena que va acompañada de tres asistentas, que portan respectivamente, una sombrilla, un espejo y un cofre. Al otro lado de la nave, por la proa, los mismos cinco personajes descienden por la pasarela, para ser recibidos por dos parejas de danzantes con indumentaria frigia, ante una construcción amurallada identificable con Troya.

La escena D, está ubicada igualmente en ese lado oriental de la sala. En ella se plasma un cortejo dionisiaco en el que el dios representado como un joven de largos cabellos, aparece subido en una cuadriga tirada cubierta por un pardalis, y tirada por cuatro centauros músicos que tocan el aulos y la siringa. El carro es antecedido por el resto de personajes asociados a este thiasos: ménades, sátiros, el dios Pan, Sileno y animales de filiación oriental.

Los pasajes de la vida del dios cuenta han sido asiduamente representados por lo que existen múltiples paralelos en la musivaria hispana. Por citar alguno mencionaremos el descubierto en la domus situada en la calle Espíritu Santo de Écija (León et alii 2010: 66). Otro ejemplo lo recogía el mosaico perdido de Dionisos de Sagunto (López 2004; 195). Sin olvidar el solado de la villa de Fuente Álamo en Puente Genil, Córdoba (San Nicolás 1997: 406ss; Lancha 2001: 165), o el 
maltrecho mosaico de Baños de Valdearados (Argente 1975: 901; 1979: Blázquez 2010: 94). Son muchos los ejemplos de escenas báquicas, por lo que eludimos la enumeración de todos, pero no podemos dejar pasar el destacado cortejo dionisíaco de Torre de Palma en Monforte, Portugal, donde aparecen un número de quince personajes formando parte del thiasos (Blázquez 1980: 128), casi tantos como en el mosaico de Noheda.

La escena E, localizada y orientada hacia la parte meridional de la sala es muy similar al panel B arriba mencionado, apreciándose solamente ligeras variaciones en la posición y dinamismo de las figuras, así como en el cambio de orientación de determinados personajes. Como en el caso antes analizado, las escenas menores son alusivas a ludi.

Por último, la escena F parcialmente destruida por la caída de la cúpula de la estancia, representa diversos motivos marinos, - escenas de pesca, erotes, tritones y nereidas -, acordes con la naturaleza acuática del estanque que enmarcaban.

Como en el caso anterior, la representación del thiasos marino en la musivaria romana es un tema muy recurrente en todo el imperio, baste con consultar la dilatada bibliografía existente (López 1988a: 38ss; Neira 1991: 514ss; 1994a: 1261; 1994b: 360; 1997: 364; 2002: 16ss; 1997: 265ss; San Nicolás 2004-2005 310-314) para comprobar la ingente cantidad de pavimentos que cuentan con este tema. Aunque creemos obligado destacar la escena de nereidas que junto a tritones aparecen en el mosaico italicense del Nacimiento de Afrodita/Venus descubierto en 1973 (Canto 1976: 293), en el que aparecen dos ejemplares con epigrafía, uno de ellos flotando sobre los lomos de un toro marino a cuyos cuernos se aferra y otro que da la espalda al espectador (León et alii 2010: 116).

Hay que resaltar la gran calidad técnica conseguida a la hora de ejecutar el mosaico del triclinium de Noheda, que parece una obra pictórica más que musivaria. Se trata por tanto de pavimento realizado en su mayor parte de opus vermiculatum, con teselas milimétricas - algunas de ellas de $1,5 \mathrm{~mm}$. - de una variadísima gama cromática, utilizándose para determinados tonos piezas de pasta vítrea e incluso doradas. Se consiguen así infinidad de matices, destacando el cuidado estudio anatómico del cuerpo humano, el dinamismo de las figuras en movimiento y la expresividad de los personajes.

Por múltiples razones el mosaico de Noheda es excepcional, no conociéndose en territorio hispano ningún otro pavimento figurativo con estas dimensiones. Además resulta complicado buscar otros ejemplares musivarios en todo el Imperio con características análogas a éste, es decir, que cuenten con su gran profusión iconográfica y tan compleja y variada composición. A todo esto se suma el excelente estado de conservación, habiendo perdido, tal y como se he indicado, sólo una pequeña parte de su superficie, que en modo alguno afecta a la interpretación global de las escenas. A nuestro entender se trata de un unicum dentro de la producción musivaria conservada en ámbito hispano, pero también en todo el imperio romano. 


\subsection{Propuesta de delimitación del Fundus de Noheda}

A la hora de establecer una propuesta del ámbito de desarrollo del fundus de la villa de Noheda, no tiene sentido la delimitación actual administrativa, de manera que el estudio diacrónico del territorio no se realizará sobre los términos municipales actuales (Arrancacepas, Bascuñana de San Pedro, Cañaveras, Cuenca, Chillarón de Cuenca, Mariana, Sotorribas, Torralba, Villar de Domingo García, Villar y Velasco y Villas de la Ventosa), que no conforman una unidad territorial coherente. Por el contrario, se atenderá a una delimitación espacial basada fundamentalmente en factores geográficos y culturales (Mee y Forbes 1997: 33), lo que en ocasiones implica dificultades nominales, además de otras de orden práctico.

Por ello la opción por la que hemos nos hemos decantado a la hora de acotar la zona, es que el área elegida responde a unas demarcaciones geográficas ordenadas en torno a los sistemas montañosos y varias cuencas fluviales, lo que entendemos que puede corresponder una unidad económica romana de este tipo de grandes complejos agropecuarios, ya que contiene terrenos susceptibles de ser integrados por el fundus de una villa y por tanto de ser explotados y aprovechados por estas fincas. De este modo, en la delimitación propuesta se distinguen, el ager entendiendo como tal las propias tierras de cultivo que circundan la quinta; el saltus, siendo éstos los espacios dedicados a la vida pastoril y que corresponden con las alcarrias actuales donde son comunes las suaves lomas y pequeños oteros con monte bajo y herbáceas idóneas para el aprovechamiento pecuario. Por último, la silva que es el propio bosque de aprovechamiento maderero y de recolección de frutos silvestres que recae en las sierras de Bascuñana y Cabrejas.

Las fronteras propuestas para el fundus estudiado son: la Sierra de Bascuñana al este, la Sierra de Cabrejas en su franja occidental, el río Guadamejud en el sector norte, mientras que el río Júcar cierra al sur, este amplio territorio de 25 $\mathrm{km}^{2}$. Es decir una extensa semi-llanura con presencia de altos y apuntados cerros, aplanados páramos, extensas campiñas y profundos valles (Asensio et alii 1998: 231), que se encuentra bien regada y articulada por las cuencas hidrográficas de los ríos, Júcar, Chillarón, Guadamejud y Mayor, con sus respectivos cursos fluviales tributarios. (Fig. 3)

Nuestro interés por esta área se centra, por un lado, en analizar el importante factor de ordenación territorial que supuso en época romana la villa de Noheda y por otro, porque la presencia en este espacio geográfico de varios subtipos de unidades fisiográficas, ofrecen elementos de utilidad, y muy especialmente la posibilidad de analizar el patrón de explotación agropecuaria del territorio diseñada por la quinta, para la zona de los valles, de los altos páramos, las áreas llanas, o los apuntados cerros y las estribaciones montañosas. Con ello esperamos encontrarnos con diferentes respuestas de adaptabilidad agrícola al medio.

En síntesis el objetivo de este trabajo, será intentar definir el tipo de poblamiento de las comunidades asociadas a la villa allí establecidas, determinar las 
influencias del medio físico sobre el hombre, al tiempo que éste sobre aquel y llevar a cabo un análisis diacrónico desde el punto de vista histórico y cultural del entorno de la villa romana de Noheda, valorando las transformaciones sufridas como consecuencia de su aprovechamiento en las diferentes etapas de explotación.

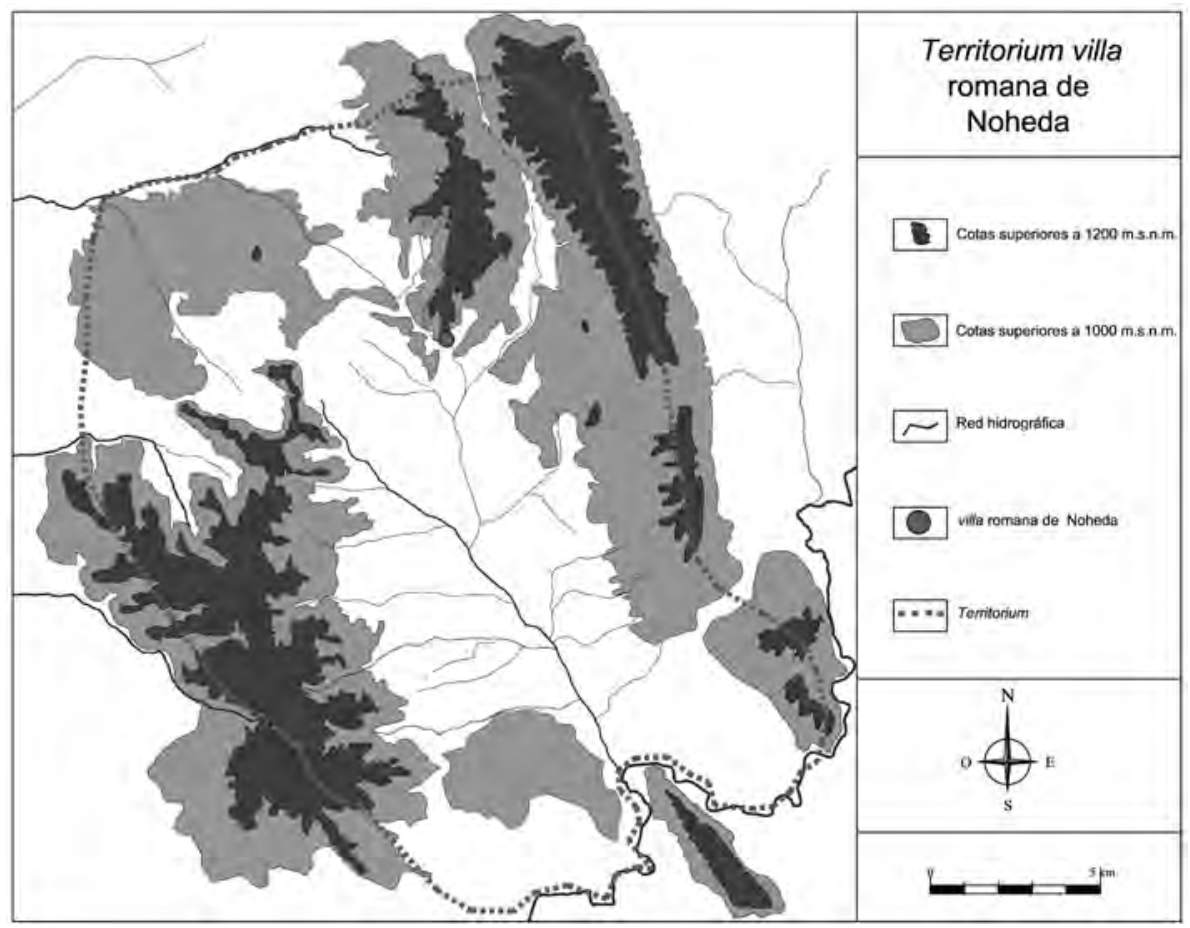

Figura 3 - Propuesta del fundus de la villa romana de Noheda.

\subsection{El MEDio FÍsico}

El conocimiento del marco geográfico en el que se desarrolla una determinada cultura constituye un requisito fundamental para el estudio y comprensión de la misma, teniendo en cuenta que éste influye directamente en la conducta humana, haciendo que las actividades antrópicas estén orientadas a responder ante ese marco espacial. La respuesta es bidireccional: el hombre estará condicionado por el medio físico y éste a su vez estará siendo modificado constantemente por el primero. Lógicamente el nivel tecnológico de que disfruta el hombre en cada momento incide en su capacidad de transformación del entorno. De este modo, sociedades como la romana, cuyo grado de desarrollo tecnológico es elevado, el grado de afección antrópico sobre el medio es bastante acusado, al intentar extraer el máximo rendimiento posible. 
Para la configuración y descripción del marco geográfico se ha recurrido en determinados casos a datos actuales, siendo conscientes de que el medio ambiente está constantemente sometido a pequeñas o grandes transformaciones. Por ello, la mayoría de la información usada para la reconstrucción del paisaje en esta área para época romana se ha basado en los análisis faunísticos, palinológicos, carpológicos y antracológicos efectuados en el transcurso de nuestras investigaciones efectuadas en la propia villa.

El entorno de Noheda se caracteriza por orografía cambiante donde las áreas llanas de las campiñas se alternan con los elevados páramos, altos cerros o profundos valles (Asensio et alii 1998, 231). Además las cordilleras montañosas delimitadoras cuentan con un agreste relieve constitutivo de la Sierra de Bascuñana (Gesteiro 1998: 245) y un abrupto y compacto contrafuerte rocoso en la Sierra de Cabrejas (Alonso 1998: 265). Su ubicación geográfica en el contexto peninsular, marcando un "paso sencillo" de sur a norte, y de este a oeste, entre los accidentados macizos antes mencionados, hacen de esta zona una vía natural de comunicación (Valero 1999b: 213; 1999c: 14; 2008: 180) que recorren varias calzadas romanas (Abascal 1982: 68; Palomero 1987; 156 Valero 2013b: 233).

$\mathrm{El}$ paisaje de la comarca es variado con indudables contrastes visuales entre zonas llanas, valles y cerros. Pero sin duda, la tipología paisajística que identifica a este espacio son los páramos y las alcarrias, con sus cuestas acarcavadas coronadas por planicies. Terminan por dibujar el panorama las arboledas de encinas, robles y pinos, que sirven de introducción a la sierra y las alamedas en el fondo de los valles que dan un colorido cambiante con el paso de las estaciones, acompañadas por los colores rojizos de las plantaciones de mimbre (Peinado et alii 2008: 26). (Fig. 4)

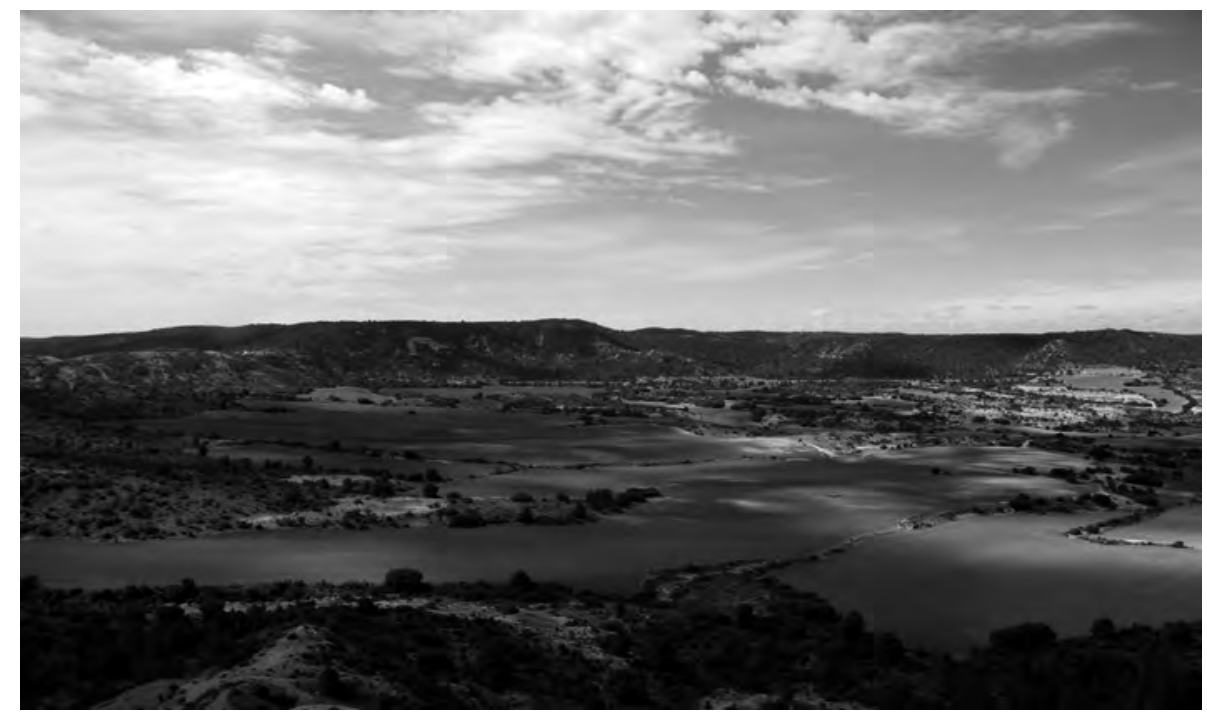

Figura 4 - Paisaje circundante de la villa. 
La estratigrafía geológica está marcada por las diversas formaciones del Terciario sobre las que apoyaron en las zonas de los valles las tierras cuaternarias, si bien las sierras contienen materiales formados en época Jurásica (Gesteiro 1998: 250-251). Esta etapa geológica es la responsable del tipo de suelos, que no olvidemos, es una de las variables ambientales con mayor peso específico en la explotación económica de un territorio. En el entorno de Noheda encontramos fundamentalmente suelos pardo-rojizos con superficie caliza. Éstos, unido a la inexistencia de aguas a escasa profundidad, así como en la costra superficial, explican la presencia de cultivos como el girasol y cereal. Al mismo tiempo no resultan extrañas las producciones hortofrutícolas en las proximidades a los cauces de agua. Por otra parte, donde el relieve es más acusado y las tierras se vuelven más calizas con ligeras concreciones de limos arenosos (Estébanez 1974: 12), es frecuente la explotación de secano centrada en olivos, motivada por la escasa necesidad del líquido elemento y nutrientes que estos árboles requieren. Esta realidad geológica debió jugar igualmente un papel importante para la fase cronológica ahora analizada, donde las explotaciones intensivas del terreno fueron en constante crecimiento. Los habitantes de estas zonas debieron aprovechar positivamente las ventajas de explotación ofrecidas por estos suelos.

Desde el punto de vista hidrológico, como hemos apuntado más arriba, los terrenos analizados quedan insertos en el ámbito de influencia de la cuenca fluvial de los ríos Júcar, Chillarón, Guadamejud y Mayor, así como varios arroyos o ramblas de dispar caudal. El aprovechamiento únicamente de los cauces fue en muchos casos suficiente para las necesidades hídricas generadas por un hábitat disperso en pequeños asentamientos con un marcado carácter agropecuario, tal y como ocurría en el Arroyo del Egidillo (Valero 2010: 184). No obstante, la propia villa con mayores necesidades sobre todo para la imponente pars urbana, aparte de surtirse del río, contó con otros apoyos como es la existencia de una capa freática a escasa profundidad gracias a su ubicación próxima a varias surgencias de agua, que garantizaba agua a la población (Mejías et alii 2013: 16; Martínez et alii 2014: 1).

Por lo que respecta a la vegetación, los mencionados análisis palinológicos, carpológicos y antracológicos efectuados en la villa de Noheda, han identificado 23 taxones de los que 6 son arbóreos, 3 arbustivos, 14 herbáceos, junto a 3 elementos acuáticos (Cyperaceae, Nymphaceae y Typha monada), y 10 micro-fósiles no polínicos (MNP) de afinidad diversa. La composición del grupo arbóreo (Quercus tipo perennifolio y caducifolio, Oleaceae, Pinus y Juniperus y presencias de Abies), es indicativa de un paisaje de tipo mediterráneo relativamente próximo a un cauce, hecho que justifica la presencia de los taxones de ribera (Salix y Ulmus). El estrato arbustivo no tiene un papel relevante en el paisaje vegetal. En cuanto a la composición del conjunto herbáceo, cabe destacar el dominio de las Asteraceae liguliflorae y Asteraceae tubuliflorae, Poaceae y en menor medida Chenopodiaceae, junto a un variado conjunto de plantas, relacionado con la presencia del hombre. En cuanto a los MNP detectados y cuyo desarrollo está estrechamente relaciona- 
do con la naturaleza del medio, destacan los de afinidad coprófila (Sordaria o tipo 55 A y Podospora o tipo 368), los de carácter meso-eutrófico (tipos 16, 174, 181) y Glomus o tipo 207, asociado a procesos de deforestación.

La vegetación actual está muy alterada, el desarrollo de la agricultura extensiva junto a la tala desmedida de gran parte de la flora original, ha creado un paisaje distinto desde época romana hasta nuestros días. Así en las parameras, por su particular disposición orográfica, existe una vegetación compuesta mayormente por sabinas albares y enebros. Por su parte, las campiñas y los fondos de los valles cuentan con pequeñas machas arbóreas de chopos y olmos, cercanas a los cauces de agua. Las laderas y cimas de las elevaciones se tupen con quejigares, encinas y pinos (Asensio et alii 1998: 238).

\subsection{Metodología Propuesta}

En un estudio de análisis y evolución territorial, lógicamente el método de trabajo a emplear es la prospección arqueológica. A través de la misma se pueden localizar todos los yacimientos con cierta entidad en el área estudiada y gran cantidad, sino todos, los núcleos subsidiarios de diversa funcionalidad, ya sean de sustento económico mediante el aprovechamiento agropecuario e industrial, o los de carácter defensivo. Es por ello, que la técnica a aplicar será la prospección intensiva, pasando a especialmente intensa en determinados puntos que por geografía, toponimia o ubicación, cuenten con altas probabilidades de contener vestigios arqueológicos.

De cara a un mejor abordaje del trabajo de campo, se están efectuaron toda una serie de labores previas a la inspección ocular del terreno cuya finalidad es recopilar la mayor información posible acerca del área a estudiar. Como paso ineludible se han consultado las Cartas Arqueológicas municipales ${ }^{2}$. Esta información será utilizada para corroborar la existencia o no de un yacimiento, pero únicamente como punto de partida, ya que llegados al enclave se documentará completamente como si fuese inédito.

Por otro lado, aparte de la necesaria consulta bibliográfica, se está prestando especial atención a las fuentes históricas de cada uno de los municipios susceptibles de integrar el fundus de la villa de Noheda. De este modo, mediante la de las Relaciones Topográficas de Felipe II, se ha comprobado como en el interrogatorio efectuado, en contestación a la pregunta 36, se contesta que alu-

\footnotetext{
${ }^{2}$ Las Cartas Arqueológicas de la zona susceptible de integrar el fundus de Noheda no se han realizado en su totalidad ya que pese a ser financiadas, por el Grupo de Acción Local CEDER LA ALCARRIA, la Junta de Comunidades de Castilla La Mancha y los municipios interesados, algunos de los municipios no se ha acogido a este tipo de ayudas por lo que el trabajo en sus términos municipales no está realizado con la consiguiente merma de información preliminar en estas áreas, que esperemos sea suplida con las tareas proyectadas en esta investigación.
} 
diendo en muchos casos a la presencia de yacimientos arqueológicos indicando la aparición de restos, e incluso otorgando acertadamente la cronología de los mismos (Zarco Cuevas 1575: 313). Por otro lado, el examen del Catastro del Marqués de la Ensenada fechado en 1753, entre otros datos, ayuda a buscar la presencia y ubicación de restos de minería, tanto coetánea al interrogatorio, como anterior al mismo lo que auxilia la indagación acerca de explotaciones antiguas como las minas de lapis specularis tan comunes en la zona de Torralba. No se puede obviar el dictamen ofrecido por las respuestas de Tomás López de 1786, que describen profusamente los centros históricos así como la economía del municipio, o el diccionario Madoz de 1845-1850 (1987: 187) se realiza una exhaustiva descripción de los principales caminos transitados en la época, datos que unidos a otros, nos sirven para la realización del estudio de la caminería histórica y sus pervivencias sobre itinerarios anteriores.

La consulta de Mapas Topográficos del Servicio Geográfico del Ejército y del Instituto Geográfico Nacional es obligada para los estudios de prospección. Por ello se están utilizando cartografía de escala 1:50.000 y 1:25.000, tanto moderna como antigua, así como los catastros actuales a escala 1:5.000 y los denominados "catastrones" ${ }^{3}$ de escala 1:10.000 fechados en 1908, donde la obtención de referencias acerca de microtopónimos, o de estructuras históricas susceptibles de ser elementos inventariables resulta patente. Además se está trabajado con las imágenes disponibles gracias al Plan Nacional de Ortofotografía Aérea (PNOA), así como con las fotografías del denominado "vuelo americano", todas estas herramientas que están siendo intensamente analizadas, una vez georreferenciadas y volcados los datos extraídos en el plano matriz que se genera con la asunción de todos los testimonios anteriormente citados. (Fig. 5)

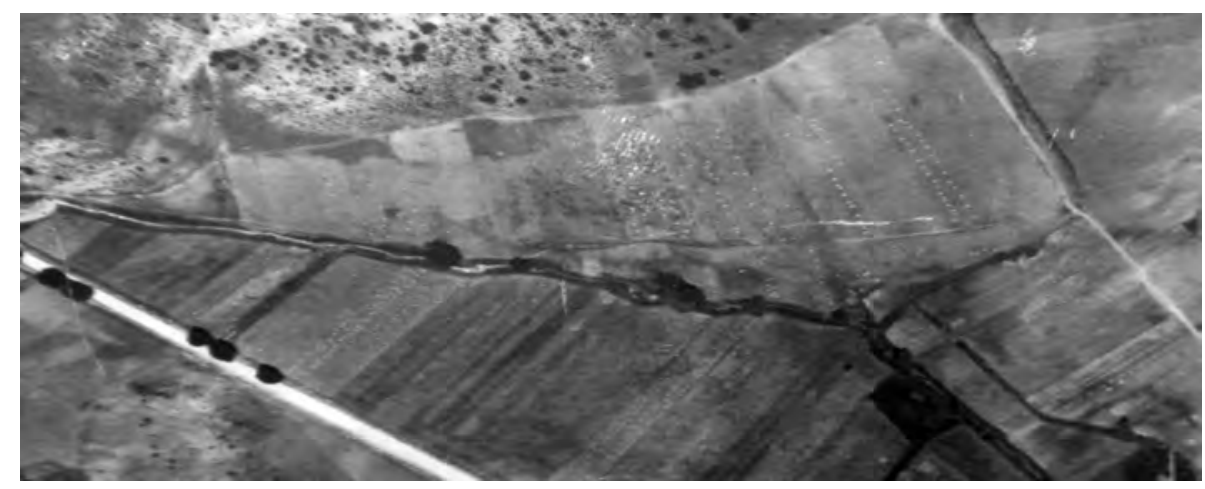

Figura 5 - Detalle de la zona donde se ubica el yacimiento, procedente de las fotografías aéreas del denominado vuelo americano.

${ }^{3}$ Agradecer desde aquí al Archivo Histórico Provincial de Cuenca, las facilidades otorgadas para la consulta de estos mapas, así como de las fotografías aéreas de 1956 del vuelo americano. 
La última actividad dentro de esta fase de documentación previa es la realización de entrevistas a varios habitantes de los distintos pueblos. Esta técnica está basada en la obtención de datos procedentes de la sabiduría popular, ya que consideramos que el mejor conocedor del lugar es la persona que lo habita y lo trabaja, pues es quién percibe cualquier anomalía en el terreno. Con la modernización agrícola, las nuevas máquinas empleadas en tareas de desfonde introducen las rejas del arado a una mayor profundidad de lo que se hacía antaño, cuando se empleaba tracción animal. El agricultor percibe con claridad la aparición de lo que ellos denominan "pucheros morunos", hecho que manifiesta si se le pregunta directamente por el tema.

Tras la profusa preparación previa, se pasará al trabajo de campo. La primera cuestión a resolver en el planteamiento de la prospección, una vez marcadas las fronteras naturales o administrativas que acotan la zona, es cómo llevarla a cabo, es decir la metodología de prospección a seguir. En este sentido es fácilmente deducible que las técnicas de prospección deben adecuarse a la zona a tratar y no viceversa. Esto cobra especial relevancia en el área donde se inserta la villa de Noheda, la Alcarria Conquense, caracterizada por la alternancia entre paisajes llanos, pequeñas y medianas lomas y presencia de algunos picos montañosos, no excesivamente elevados pero sí apuntados. Por ello, es indispensable partir de unos criterios geográficos, aplicando la sistemática de transects, o de la división agrícola del terreno, en las zonas más o menos llanas, lo que permite una mayor rentabilización de resultados, mientras que en las superficies montañosas se empleará el sistema usado y de demostrada eficacia en varios ámbitos del Mediterráneo (Gómez et alii 2005: 29; 2011: 8), que es la división por terrazas o cotas.

Queremos llamar la atención sobre la realidad del espacio a analizar, compuesto tal y como hemos apuntado, a parte iguales por zonas semi-llanas donde se ha desarrollado una agricultura extensiva y por tanto la visibilidad de terreno es óptima, y topografía abrupta donde la vegetación existente en la actualidad se compone de monte bajo o pinares, con la consecuente dificultad (sobre todo de éstos últimos) en visionar el suelo, ya que se encuentra completamente cubierto por pinocha.

El rastreo se efectuará con una interdivisión de los miembros del equipo de 25 o $50 \mathrm{~m}$. en las zonas bajas, pero se intensificará a $5 \mathrm{~m}$. en áreas de denso bosque o de mala visibilidad. En un espacio tan densamente antropizado y donde los procesos deposicionales y postdeposicionales tienen un peso importante, la determinación de la existencia o no de un yacimiento, implicará la localización de una concentración cerámica superior a 16 fragmentos por $100 \mathrm{~m}^{2}$, independientemente de la existencia o no de estructuras emergentes. Para una mejor comprensión y valoración del concepto de yacimiento seguiremos la metodología anglo-sajona, de demostrada eficacia, que distingue diametralmente entre hallazgos on-site y off-site (Bintliff, 2000: 202-214). De este modo, las densidades fragmentos cerámicos que permiten hipotetizar sobre la existencia de estructuras 
soterradas, varía entre 50 y 300 hallazgos en $100 \mathrm{~m}^{2}$. Mientras que la presencia de material residual, - entre 1 y 15 fragmentos - indica la presencia de algún tipo de actividad humana, como pueden ser, hábitat estacional, laboreo agrícola, etc. (Cherry et alii 1991: 45-53). El hecho de localizar algún fragmento cerámico, conllevará el rastreo meticuloso con una separación de $2 \mathrm{~m}$. entre prospectores. Se delimitará el área de dispersión cerámica y contaremos los fragmentos, además de aplicar un baremo de 1 a 15, relativo al grado de concentración de los mismos como variable para identificar hábitats o de explotación agrícola y sobre todo para determinar la zona nuclear o de dispersión cerámica de un yacimiento, más si cabe en esta zona donde el laboreo agrícola ha podido desplazar los vestigios arqueológicos desde su punto de origen. Los yacimientos en los que se detecten estructuras emergentes constituirán un caso aparte ya que éstas facilitan su delimitación, aunque sin perder de vista que la demarcación apreciable en superficie no tiene por qué coincidir con los límites reales del asentamiento.

A continuación se recogerá el material más significativo que ayude a identificar el origen y la datación del enclave, dejando el resto in situ, para no esquilmarlo. Para éste hecho se seguirá la bibliografía específica (Vegas 1964; Beltrán 1990; Abascal 1996; 2008; Luezas 2002; Bernal y Lagóstena 2004; Serrano 2008).

La gestión del amplísimo volumen de información generado (Fernández 2003: 173), se articulará mediante el desarrollo de un Sistema de Información Geográfica, herramienta de reconocida eficiencia (Sáez et alii 2000:26), que contiene un importante cuerpo de datos tanto de carácter gráfico como alfanumérico, referidos a la realidad arqueológica encontrada. Con ello se están marcando unos protocolos de trabajo de prospección que permitirán la recogida de información en campo, así como su volcado en la base de datos, para su integración en un S.I.G., en el propio yacimiento. Esto es así porque consideramos que la plasmación de la documentación exacta resulta fundamental, de tal modo que evitaremos la degradación de la información desde su adquisición en el propio enclave hasta su ulterior volcado en el Sistema. Para ello, se ha desarrollado un procedimiento que permite la toma de datos in situ directamente en un ordenador de mano dotado de G.P.S. (concretamente una Tablet iPad 2) al cual se le ha insertado el pertinente software cartográfico, con los arriba mencionados planos matrices. Como en otros estudios (Sáez et alii 2006: 149), con esta metodología se sustituirá el procedimiento tradicional, consistente en el relleno de fichas sobre el terreno anotando la ubicación y delimitación de los yacimientos -con o sin G.P.S.-, además de sobre la base de cartografía en papel. Es bien conocido que este sistema está sujeto a errores o carencias en cuanto a la calidad de la información, sobre todo a la hora de su transmisión a la documentación final y al S.I.G.

De este modo, los datos de delimitación de los elementos arqueológicos se introducirán in situ, visualizando en pantalla sobre el mapa ráster y las ortofotografías, la localización en la que nos encontramos en cada momento. Asimismo, las anotaciones de campo y la cumplimentación de fichas también se llevarán a 
cabo en el ordenador de mano. La realización de todo el proceso directamente en el yacimiento, implicará una mayor precisión, además de la posibilidad de un primer análisis todavía en campo, por lo que se podrá profundizar sobre algunas cuestiones como la intervisibilidad con otros enclaves, la caracterización fisiográfica y paleogeográfica del terreno circundante (llanura, ladera, cima, espolón, etc.) y una incipiente, pero reveladora, evaluación de los recursos existentes, especialmente las capacidades agropecuarias y mineras de las tierras.

Con todos estos datos aplicaremos las directrices de la arqueología del paisaje, que nos ayudará a analizar factores explicativos del patrón de asentamientos y sus variaciones en diversas épocas (inicialmente nos ceñiremos a la Romanización), distribución espacial y explotación territorial (agrícola, ganadera o minera), jerarquización de enclaves habitacionales, su evolución diacrónica y las interconexiones con las vías de comunicación.

\subsection{LOS PRIMEROS DATOS: LA EVOLUCIÓN DEL PAISAJE}

La evolución de la explotación territorial en época romana, no se puede interpretar adecuadamente sin intentar conocer y comprender los cambios y la evolución que el paisaje en las fases históricas posteriores a la analizada.

Para conocer éstas últimas hemos recurrido a las fuentes históricas que nos indican el desenvolvimiento agrícola, ganadero, minero y sobre todo del tipo de vegetación existente desde el siglo xv (Zarco Cuevas 1575: 141-145; 192-199), hasta nuestros días, haciendo especial hincapié en los siglos xviıI (Catastro de Ensenada 1753 y Diccionario de Tomás López 1786) y xix (Diccionario de Madoz). De este modo, comprobamos como la zona analizada empieza a reflejar una mayor ocupación del terreno para el desarrollo de los cultivos, ya no ciñéndose a los valles donde la afluencia de agua está garantizada, sino a la totalidad del espacio que orográficamente es susceptible de ser aprovechado, a partir de mediados del siglo $\mathrm{xx}$.

La cubierta vegetal tal y como hemos apuntado, si la intervención del hombre no se hubiera producido, se adaptaría al bosque mediterráneo compuesto por pinos, encinas, robles y algún arbusto como las sabinas y enebros. Los herbáceos son fundamentalmente tomillos, romeros, aliagas y esparto. La agricultura ha alterado este tipo de cubierta, pero incluso ésta ha cambiado a lo largo de los años, transformando el paisaje agrario de época moderna, probablemente heredado de las etapas precedentes. De este modo, en el siglo XV resultaban muy abundantes los viñedos, cultivo que en el siglo Xviı (AHPC legajo 959/7) aún se mantenía, llegando hasta mediados de la centuria siguiente (Madoz 1987: 187). Éstos ocupaban las zonas llanas de las campiñas, esparcidas en pequeñas parcelas. Hoy en día solamente quedan algunos testigos de este tipo de explotación.

Sí que se han mantenido inalterables a lo largo del tiempo, los campos dedicados al cereal - sobre todo trigo y cebada - y los olivos, si bien han cambiado 
los porcentajes y su distribución. Así las cosas, el cereal ha ganado espacio a costa de las mencionadas viñas, conquistando la totalidad de las parcelas. Por otro lado, los olivares que se encontraban distribuidos en reducidas propiedades que ocupaban las empinadas laderas de las alcarrias y los cerros, transformándolas en vistosas terrazas únicamente trabajadas mediante tracción animal, con la llegada de la mecanización al campo, fueron trasladados a las partes bajas de esos oteros, formando amplias parcelas dedicadas a esta labor. También parecen fosilizadas, al menos en determinadas zonas como la propia Noheda, las vegas de los cursos fluviales. En época romana estaban densamente ocupadas por cultivos de árboles frutales como, manzanos y perales, que alternaban entre frondosas choperas, junto a pequeñas pero fértiles huertas donde las hortalizas estaban patentes. Y así las encontramos hoy en día, en una buena parte del cauce de los ríos con caudal regular.

Consideramos que en época romana, tanto la cubierta vegetal como el aprovechamiento campesino no fuera muy diferente al descrito por los textos históricos. Así en el mencionado estudio palinológico de la villa de Noheda se manifiesta una paulatina antropización del espacio territorial a partir del siglo I con una progresiva pérdida de masa arbórea en favor de los cultivos centrados en la tríada mediterránea, con olivos y cereales a partes iguales, si bien las viñas resultan mayoritarias. Hortalizas, legumbres y frutales completan el espectro. Nos encontramos pues, con idénticos taxones que los reflejados por las fuentes históricas lo que apoya la creencia de que el paisaje descrito por las mismas no variaría mucho de las etapas precedentes, en mayor o menor grado de intensidad en la producción.

Pero desde mediados del siglo xx hasta nuestros días la evolución del paisaje ha sido vertiginosa, con una transformación del entorno acelerado, cuyo punto de origen fue la mecanización del campo que ha metamorfoseado drásticamente el paisaje e incluso el parcelario, aglutinando las pequeñas explotaciones en grandes fincas, con la consiguiente pérdida de información histórica sobre el repartimiento de las tierras en la antigüedad. Las transformaciones agrícolas han sido especialmente intensas en los cultivos de secano. Así a la comentada práctica eliminación de la masa de viñedos, se le suma la introducción de cultivos como el girasol que ocupa el mismo espacio que los cereales, alternando las parcelas junto con los barbechos para obtener un mayor rendimiento. Las laderas de los cerros fueron completamente abandonadas, dejando solo despobladas terrazas como testigos de la ocupación oleícola que tuvieron antaño. Frutales y hortalizas resultan en la actualidad poco significativos, concentradas como hemos apuntado en los cauces fluviales.

Al contrario que en otras zona próximas (Valero 2013b: 262), los dos primeros tercios del siglo xx no supusieron la degradación de la silva romana, pese a talas realizadas la reforestación del bosque, eso sí con un tipo de pino distinto al tradicional, implica que aun hoy existan grandes concentraciones arbóreas de pinos y encinas en las estribaciones serranas que delimitan el fundus de Noheda. 
También se localizan varias canteras - algunas centenarias -, dedicadas a la extracción de sillares y otras de grava, o arenas.

En definitiva, en el entorno de Noheda son más que patentes los cambios en el paisaje derivados de por el llamado progreso. Las grandes fincas han sustituido a las pequeñas parcelas centenarias. Estas transformaciones afectan al reconocimiento del poblamiento antiguo a través de la prospección. Los porcentajes de posibles yacimientos en distintas áreas del territorio, están directamente relacionadas con la conservación o el deterioro del paisaje (Pérez y Borreda, 1998: 139).

$\mathrm{El}$ avance de las intervenciones en la villa romana de Noheda, unido al descubrimiento de nuevos datos aportados por las prospecciones y la publicación de investigaciones en marcha, consolidarán o no nuestras propuestas. 


\section{Bibliografía}

ABASCAL PALAZÓN, J.M. (1982) Vias de comunicación romanas de la provincia de Guadalajara. Guadalajara, Diputación Provincial de Guadalajara.

(1996) La cerámica pintada romana de tradición indígena en la Peninsula Ibérica. Madrid.

(2008) Las cerámicas tipo Clunia y otras producciones pintadas hispanorromanas. In: Cerámicas hispanorromanas. Un estado de la cuestión. XVII Congreso Internacional de la Asociación Rei Cretariae Fautores. Cádiz, p. 429-443.

ALONSO OTERO, F. (1998) Serranía de Cuenca. In: VVAA: Guía de Castilla- La Mancha: Espacios naturales. Toledo, p. 265-281.

AMORES CARREDANO, F.; RODRÍGUEZ BOBADA, C.; SÁEZ FERNÁNDEZ, P. (2001) La organización y explotación del territorio de Carmo. Carmona romana. Carmona, p. 413-446.

ARCE, J. (2006) Villae en el paisaje rural de Hispania romana durante la Antigüedad tardía. In: Chavarría; Arce; Brogiolo (Eds.) Villas Tardoantiguas en el Mediterráneo Occidental. Madrid (Anejos de AEspa XXXIX), p. 9-15.

(2009) El último siglo de la España romana, 284-412. Madrid.

(2010) El complejo residencial tardorromano de Cercadilla (Corduba). In: Vaquerizo (ed.) Las áreas suburbanas en la ciudad bistórica. Topografía, usos, función. Cordoba (Monografías de Arqueología Cordobesa 18), p. 397-412.

(2012) Campos, tierras y villae en Hispania. In: Caballero; Mateos; Cordero (Eds.) Visigodos y Omeyas. El territorio. Mérida, p. 21-30.

ARIÑO GIL, E.; GURT ESPARRAGUERA, J.M.; PALET MARTÍNEZ, J.M. (2004) El pasado presente. Arqueología de los paisajes en la Hispania romana. Salamanca, Universidad de Salamanca.

ASENSIO, I.; GONZÁLEZ, J.A.; VÁZQUEZ GONZÁLEZ, A. (1998) Páramos y campiñas de la Alcarria. In: VVAA: Guia de Castilla-La Mancha: Espacios naturales. Toledo, p. 227-243.

BELTRÁNLLORIS,M.(1990) Guíadela Cerámicaromana.Zaragoza,PórticoLibr.

BERNAL CASASOLA, D.; LAGÓSTENA BARRIOS, N. (Eds.) (2004) Figlinae Baeticae. Talleres alfareros y producciones cerámica en la Bética romana (siglos II a.C. - VII d. C.). Oxford (BAR IS 1266).

BINTLIFF, J. (2000) The concepts of "site" and "of site" archaeology in surface artefact survey. In: Pasquinucci; Trément, (eds.) Non-destructive techniques applied to landscape archaeology. Oxford, p. 200-215. 
BLÁZQUEZ MARTÍNEZ, J. M. (2003) El Circo Máximo de Roma y los mosaicos circenses hispanos de Barcelona, Gerona e Itálica. In: Nogales; Sanchez (Eds.) El Circo en Hispania romana. Mérida, p. 197-215.

(2014) Mitos del mosaico de Cástulo. SEsq 6, p. 109-111.

BUENACASA PÉREZ, C. (2006) Mosaicos romanos de Siria. Pintura de piedra. Barcelona, Ed. Fundació Arqueològica Clos.

BUSQUIER CORBÍ, J. D. (2010) Un ejemplo de minería romana en la Meseta Conquense. La mina de Lapis Specularis de Vallejo del Castillejo. Horcajada de la Torre (Cuenca). In: Perlines Benito; Madrigal Belinchón (Eds.) Actas de las II Jornadas de Arqueología en Castilla-La Mancha, Vol. II. Toledo, cd adjunto 3.2.

CANTO, A. (1976) El mosaico del Nacimiento de Venus en Itálica. Habis 7, p. 293-338.

CARRILLO, J.R.; HIDALGO PRIETO, R. (1991) Aproximación al estudio del poblamiento romano en la comarca de Palma del Río (Córdoba): implantación territorial. Ariadna 8, p. 37-68.

CASTELLO RUANO, R.; TORRECILLA, A.; AGUADO, M.; BANGO, C.; ARRIBAS, R.; SIERRA, C. (2000) Arqueología en la comarca de la Alcarria conquense. Avance de las investigaciones sobre el yacimiento del cerro de Alvar Fáñez (Huete-Cuenca) CuPAUAM 26, p. 95-149.

CLAIRMONT, C. (1951) Das Parisurteil in der antiken Kunst. Zurich.

CRIADO, F.; BONILLA RODRÍGUEZ, A.; CERQUEIRO LANDÍN, D.; DÍAZ VÁZQUEZ, M.; GONZÁLEZ MENDÉZ, M.; INFANTE ROURA, F.; MÉNDEZ FERNÁNDEZ, F.; PENEDO ROMERO, R.; RODRÍGUEZ PUENTES, E.; VAQUERO LASTRA, J. (1991) Arqueología del paisaje. El área Bocelo-Furelos entre los tiempos paleolíticos y medievales. La Coruña (Arqueoloxial Investigación 6).

CHAVARRÍA ARNAU, A. (2005) Villas in Hispania during the fourth and fifth Centuries. In: Bowes; Kulikowski (Eds.), Hispania in Late Antiquity. Current Perspectives. Leiden-Boston, p. 518-555.

(2006) Villas en Hispania durante la Antigüedad tardía. In: Chavarría; Arce; Brogiolo (Eds.) Villas Tardoantiguas en el Mediterráneo Occidental. Madrid (Anejos de AEspa XXXIX), p. 17-35.

(2007) El final de las uillae en Hispania (siglos IV-VIII), Brepols, Turnhout (BAT 7).

CHERRY, J.F.; DAVIES, J.L.; MANTZOURANI, E. (1991) Landscape Archaeology as Long-Term History (Northern Keos in the Cycladic Islands). Los Angeles. 
CHOCLÁN, C. (ed.) (e.p.) Actividades del Proyectos Forum MMX. Excavaciones en el Centro Monumental de Cástulo 2011-2012, Conjunto Monumental de Cástulo.

DAVIDSON, I; BAILEY, G.N. (1984) Los yacimientos, sus territorios de explotación y la topografía. Boletín del Museo Arqueológico Nacional II, p. 25-46.

DEPREZ, S.; DE DAPPER, M.; DE JAEGER, C.; VERMEULEN, F. (2011) Geo-archaelogical research in the Northeastern Alentejo. In: Carneiro; Rocha; Morgado; Oliveira (ed.) Arqueologia do norte alentejano. Comunicações das 3. as Jornadas. Fronteira, p. 25-34.

DíAZ-ANDREU GARCÍA, M. (1990) Las Edad del Bronce en el Noroeste de la Meseta. Actas del Simposio sobre la Edad del Bronce en Castilla-La Mancha. Toledo, p. 145-171.

(1994) La Edad del Bronce en la provincia de Cuenca. Cuenca (Serie Arqueología Conquense 13).

DÍAZ-ANDREU GARCÍA, M.; SANDOVAL LEÓN, M.D. (1991/92) El poblamiento en la Cuenca del río Guadamejud (Cuenca) durante la II Edad del Hierro. Zephyrus XLIV-XLV, p. 331-371.

DOMINGOS PUERTAS, L.A.; MAX-MAGARIÑOS SÁNCHEZ, J.M.; ALDECOA QUINTANA, M. A. (2007) Nuevos datos sobre el poblamiento en la Carpetania meridional: el valle medio del Cigüela. Estudios sobre la Edad del Hierro en la Carpetania: registro arqueológico, secuencia y territorio, Vol. 1, p. 218-235.

DUNBABIN, K. M. D. (1978) The Mosaics of Roman North Africa. Oxford.

(2003) The Roman Banquet. Images of conviviality. Cambrige.

DURÁN, V.; PADILLA, A. (1990) Evolución del Poblamiento Antiguo en el Término Municipal de Écija. Écija.

DYSON HUDSON, R.; ALDEN SMITH, E. (1978) Human territoriality. American Antropologist 80, p. 21-41.

ESCACENA CARRASCO, J.L.; PADILLA MONGE, A. (1992) El poblamiento romano en los márgenes del antiguo estuario del Guadalquivir. Ecija.

ESEBÁNEZ ALVAREZ, J. (1974): Cuenca, estudio geográfico. Madrid, CSIC.

FERNÁNDEZ CACHO, S. (2003) Nuevas tecnologías en la gestión de la información del Patrimonio Arqueológico de Andalucía. Problemas detectados y soluciones adoptadas. In: Martín de la Cruz; Lucena Martín (Eds.) Actas del I Encuentro Internacional de Informática Aplicada a la Investigación y la Gestión Arqueológica. Córdoba, p. 169-184. 
FERNÁNDEZ GALIANO, D. (2010) El triunfo del amor: mosaico de Paris y Helena de Noheda. In: Neira (Ed.) Mitología e Historia en los mosaicos romanos. Madrid, p. 111-136.

FERNÁNDEZ OCHOA, C.; GI|L SENDINO, F.; OREJAS SACO DEL VALLE, A. (2004) La villa romana de Veranes. El complejo rural tardorromano y la propuesta de estudio del territorio. $A E s p A 77$, p. 197-219.

GARCÍA VARGAS, E.; ORIA SEGURA, M.; CAMACHO MORENO, M. (2002) El poblamiento romano en la campiña sevillana: el término municipal de Marchena. Spal 11, p. 311-340.

GESTEIRO ARAÚJO, M.; (1998) La Sierra de Altomira. In: VVAA: Guia de Castilla-La Mancha: Espacios naturales. Toledo, p. 245-253.

GISBERT, J.A. (2003) El territorium de Dianum-Dénia en el Alto Imperio. La Marina Alta: La producción agrícola y doblamiento. In: Abascal Palazón; Abad Casal (Eds.) Revista Canelobre. Alacant, p. 121-144.

GÓMEZ BELLARD, C.; MARÍ I COSTA, V.; PUIG MORAGÓN, R. M. (2005) Evolución del poblamiento rural en el NE de Ibiza en época Púnica y Romana. (Prospecciones sistemáticas 2001-2003). Saguntum 37, p. 27-43.

GÓMEZ BELLARD, C.; DÍEZ CUSÍ, E.; MARÍ I COSTA, V. (2011) Tres paisajes ibicencos: un estudio arqueológico. Saguntum Extra 10.

GONZÁLEZ VILLAESCUSA, R. (2002) Las formas de los paisajes mediterráneos. Jaén.

GROS, P. (2001) L'Architecture romaine, 2. Maisons, palais, villas et tombeaux, Paris.

GUISADO DI MONTI, J.C.; BERNARDEZ GOMEZ, M. J. (2002) Las Explotaciones Mineras de Lapis Specularis en Hispania. ARTIFEX, Ingeniería Romana en España. Madrid, p. 273-298.

(2003) La Minería Romana de Lapis Specularis, una minería de interior. Investigaciones arqueológicas de Castilla-La Mancha. Junta de Comunidades de Castilla - La Mancha. Toledo, p. 245-256.

GUTIÉRREZ GONZÁLEZ, J. A. (2010) Modelos de transformación del paisaje antiguo y configuración de los nuevos espacios de ocupación en el norte peninsular. Actas del curso A Limia en época Medieval, Universidad de Vigo - Universidad de Ourense, p. 1-26.

HARKE SMITH, C F. (1981) Land use, burial practice and territories in the Peak District, C 2000-1000 BC. In: Barker (Ed.), Essays in social prehistoric reconstruction, p. 57-72. 
HENARES GUERRA, M. T. (2001) El bosque de Cote: una aproximación al paisaje antiguo y medieval de Montellano (Sevilla, España). Archeologia Medievale 28, p. 607-623.

HIDALGO PRIETO, R. (1998) El triclinium triconque del palatium de Córdoba. Anales de Arqueología Cordobesa 9, p. 273-300.

(2014a) ¿Fue Cercadilla una villa? El problema de la función del complejo de Cercadilla en Corduba. Archivo Español de Arqueología 87, p. 217-241.

(2014b) Aspetti dell'interpretazione del complesso palatino di Cercadilla a Cordova. La Villa Restaurata e i Nuovi Studi sull'Edilizia Residenziale Tardoantica. Atti del Convegno Internazionale del Centro Interuniversitario di Studi sull'Edilizia abitativa tardoantica nel Mediterraneo. Bari, p. 533-542.

JOHNSTON, D.E. (1983) Roman Villas. Aylesbury Shire.

LEVI, D. (1947) Antioch Mosaic Pavements. Princeton.

LÓPEZ MONTEAGUDO, G. (2014) El mosaico de los Amores de Cástulo. SEsq 6, p. 117-125.

LÓPEZ-ROMERO, E. (2011) Arqueología del Paisaje y técnicas estadísticas para el conocimiento del megalítismo de la cuenca del Server: el análisis discriminante como método de clasificación. In: Carneiro; Rocha; Morgado; Oliveira (Ed.) Arqueologia do norte alentejano. Comunicaçôes das 3. as Jornadas. Fronteira, p. 83-94.

LORRIO ALVARADO, A.J. (2001) Ercávica: la muralla y la topografía de la ciudad. Madrid.

LUEZAS PASCUAL, R.A. (2002) Cerámica común romana en La Rioja. Logroño.

MAOZ, P. (1987) Diccionario Geográfico-Estadístico de España y sus posesiones de ultramar. Castilla-La Mancha, Edición facsímil, Tomos I y II. Madrid.

MAR, R.; VERDE, G. (2008) Las villas tardoantiguas: cuestiones de tipología arquitectónica”. Fernández Ochoa; García Entero; Gil Sendino (eds.) Las villae tardorromanas en el occidente del imperio: Arquitectura y Función. Gijón, p. 50-83.

MARTÍNEZ GONZÁLEZ, J. (1988) Cerámicas campaniformes de la provincia de Cuenca. Trabajos de Prebistoria 45, p. 123-142.

MARTÍNEZ GONZÁLEZ, J.M.; MARTÍNEZ NAVARRETE, M. I. (1988) La primera ocupación del Castillo de Huete (Cuenca).Actas de $1^{\circ}$ Congreso de Historia en Castilla-La Mancha Vol. III. Ciudad Real, p. 217-227.

MARTÍNEZ NAVARRETE, C.; MEJÍAS MORENO, M.; GOICOECHEA GARCÍA, P.; VALERO TÉVAR, M.A. (2014) Posibilidades de 
abastecimiento subterráneas de la villa romana de Noheda y características geológicas de su entorno - Cuenca.

MARTÍNEZ NAVARRETE, I. (1988a) La Edad del Bronce en la Submeseta Suboriental. Madrid, Universidad Complutense (Serie Tesis Doctorales).

(1988b) Morras, motillas y castillejos: cunidad o pluralidad cultural durante la Edad del Bronce en La Mancha?. Homenaje a Manuel de los Santos. Albacete, p. 81-92.

McKAY, A.G. (1975) Houses, Villas and Palaces in the Roman World. London.

MEE, C.; FORBES, H. (1997) A Roung and Rocky Place. The Ladscape and Settlement Hustory of the Methana Peninsula Greece. Liverpool.

MEJÍAS MORENO, M.; MARTÍNEZ NAVARRETE, C.; GOICOECHEA GARCÍA, P.; VALERO TÉVAR, M.A. (2013) Estudio Geológico e Hidrológico del yacimiento arqueológico de Noheda (Villar de Domingo García, Cuenca), Instituto Geológico y Minero de España, IGME.

MONDELO PARDO, R; TORRES CARRO, M. (1985) El mosaico romano de Casariche (Sevilla). Boletin del Seminario de Estudios de Arte y Arqueología 51, p. 143-157.

MORENO MARTİN, F. (1997) Ocupación territorial hispano romana. Los vici poblaciones rurales. Espacio, Tiempo y Forma, Serie II (10), p. 295-306.

MORRICONE, Ma ${ }^{a}$ L. (1950) Scavi e ricerche a Cos (1935-1943). Relazione preliminare. Bolletino d'Arte 35, p. 219-239.

MOSCARDÓ SABATER, E. (1998) El poblamiento rural romano en el territorio norte de Dianum. La comarca de la Safor-Valldigna (Valencia). Saguntum 40, 177-192.

NEIRA JIMÉNEZ, M. L. (1991) Acerca de las representaciones de thiasos marino en los mosaicos romanos tardo-antiguos de Hispania”. Antigüedad y Cristianismo 8, p. 513- 529.

(1994a) Mosaicos romanos con nereidas y tritones. Su relación con el ambiente arquitectónico en el Norte de África y en Hispania. L'Africa romana. $X$ Convengo Internazionale di Studi. Sassari, p. 1259-1278.

(1994b) Mosaico de los tritones de Itálica en el contexto iconográfico del thiasos marino en Hispania. VI Coloquio Internacional sobre Mosaico Antiguo (Palencia-Mérida 1990). Guadalajara, p. 359-382.

(1997) Representaciones de nereidas. La pervivencia de algunas series tipológicas en los mosaicos romanos de la Antigüedad Tardía. Antigüedad y Cristianismo 14, p. 363-402. 
(2002) La representación del thiasos marino en los mosaicos romano. Nereidas y tritones. Madrid.

OREJAS SACO DEL VALLE, A. (1995-1996) Territorio, análisis territorial y arqueología del paisaje. Stvd. Hist. Antig. 13-14, p. 61-68.

(1996) Estructura social y territorio. El impacto romano en la cuenca noroccidental del Duero. Anejos de AEspAXV.

OREJAS, A.; CEPAS, A.; PLÁCIDO, D.; SÁNCHEZ-PALENCIA, F.J.; SASTRE, I.; RUIZ DEL ÁRBOL, M. (2005) La Vallée Moyenne du Guadalquivir, Paysage et territoire. Perception and evaluation of Cultural Landscapes. Proceedings of an International Symposium, Zakhynthos, p. $41-57$.

ORFILA PONS, M.; CARDELL PERELLÓ J. (1991-1992) Posible catastro romano en la isla de Mallorca. Planteamiento metodológico. Cuadernos de Prehistoria y Arqueología de la Universidad de Granada 16-17, p. 415-423.

OSUNA RUIZ, M. (1976) Ercávica I. Cuenca.

(1997) Ercávica. Ciudades romanas en la provincia de Cuenca. Homenaje a Francisco Suay Martínez. Cuenca, p. 169-207.

PALAHI GRIMAL, L.; NOLLA I BRUFAU, J. M. (2010) Felix Turissa: La villla romana dels Ametllers i el seu fundus (Tossa de Mar, la Selva). Tarragona (Documenta 12).

PALET MARTÍNEZ,J. M.; LEVEAU, P.; MOCCI, F. (1998) Arles y su territorio: Estructuras agrarias y explotación agropecuaria en época romana y medieval. Saguntum 31, p. 153-164.

PALOMERO PLAZA, S. (1987) Las vias romanas de la provincia de Cuenca. Cuenca.

PEINADO LORCA, M.; MONJE ARENAS, L.; MARTÍNEZ PARRAS, J. M. (2008) El paisaje vegetal en Castilla-La Mancha. Manual de Geobotánica. Toledo.

PENSABENE, P. (2010-2011) La villa del Casale tra Tardo Antico e Medioevo alla luce dei nuovi date archaeologici: funcioni, decorazioni e transformazioni. Rend. Pont. Acc. Arch. LXXXIII, p. 141-226.

PEÑA CERVANTES, Y. (2010) Torcularia: La producción de vino y aceite en Hispania. Tarragona, (Documenta 14).

PERCIVAL, J. (1976) The Roman Villa, A Historical Introduction. London.

PÉREZ BALLESTER, J.; BORREDA MEJÍAS, R. (1998) El poblamiento ibérico del Valle del Canyoles. Avance sobre un proyecto de evolución del paisaje en la comarca de la Costera (Valencia). Saguntum 31, p. 133-152. 
PÉREZ MÍNGUEZ, R. (2006) Aspectos del mundo rural romano en el territorio comprendido entre los rios Turia y Palancia. Valencia (Trabajos varios del SIP 106).

PONS I BRUN, E. (1984) Los orígenes acerca de la independencia $<<$ pueblo-territorio > en la llanura del Empordá (Girona). In: Burillo (Ed.) Arqueología Espacial 4. Teruel, p. 29-42.

RICHMOND, I. (1970) The plans of roman villas in Britain. In: Rivet (Ed.) The Roman Villas in Britain. London, p. 49-70.

RODRÍGUEZ RESINO, A. (2007) Ciudades, vicus, castra y villae en el NW durante la tardoantigüedad. Ensayo de un modelo arqueológico para el período. Gallaecia 26, p. 133-168.

ROMIZZI, L. (2006) Le ville tardo-antiche in Italia. In: Chavarría; Arce; Brogiolo; (Eds.) Villas Tardoantiguas en el Mediterráneo Occidental, Anejos del Archivo Español de Arqueología 39, p. 37-59.

RUBIO RIVERA, R. (2004) La ciudad romana de Ercávica. Intervenciones arqueológicas en Castilla-La Mancha 1996-2004, Toledo, p. 215-228.

(2006) Puertas y torres de la ciudad romana de Ercávica. Stadttore Bautyp und Kunstform. Puertas de ciudad, tipo arquitectónico y forma artística, Iberia Archaeologica 8, p. 185-197.

(2008) Continuidad y cambio en el proceso de Romanización del ámbito celtibérico meridional y carpetano. Iberia e Italia: modelos romanos de integración territorial, p. 127-142.

(2010) La muralla de Ercávica. Dialéctica bistórica y compromiso social, vol. 2, p. $1029-1044$.

(2013) Los orígenes de Ercávica y su municipalización en el contexto de la Romanización de la Celtiberia meridional. Vinculos de Historia 2, p. 169-183.

RUBIO RIVERA, R.; VALERO TÉVAR, M.A. (2007) Intervenciones arqueológicas en Ercávica: campañas 2003-2005. In: Rodríguez Ruza; Millán Martínez, (Eds.) Actas de las 1a Jornadas de Arqueología en Castilla-La Mancha. Cuenca, p. 431-444.

RUBIO VALVERDE, M. (2011) Estudio preliminar de una posible parcelación rural romana en el territorio de Carmo (Carmona, Sevilla). Arqueología y Territorio 8, p. 145-155.

SÁEZ FERNÁNDEZ, P.; ORDOÑEZ AGULLA, S.; GARCÍA VARGAS, E.; GARCÍA-DILS DE LA VEGA, S. (2000) Aplicaciones de los S.I.G. al territorio y casco urbano de Écija (Sevilla) (Proyecto AstiGIS). Sistemas de Informação Arqueológica. SIG's aplicados à Arqueología da Peninsula Ibérica. Porto, p. 15-31. 
(2002) Le territoire d'Astigi (Écija), La centuriation. Atlas Historique des cadastres d'Europe II, dossier 2.

(2006) Paisaje agrario y territorio en la campiña occidental de la Baetica.Arqueologia Espacial 26, p. 143-170.

SERRANORAMOS,E.(2008)Elmundodelas cerámicascomunesaltoimperiales de Hispania. Cerámicas hispanorromanas. Un estado de la cuestión. XVII Congreso Internacional de la Asociación Rei Cretariae Fautores. Cádiz, p. 471-488.

SOLÍAS ARIS, J. M. (1997) Territorium y topografía de Ercávica. Ciudades romanas en la provincia de Cuenca. Homenaje a Francisco Suay Martinez, Cuenca, p. 209-238.

TORRE, I.; LÓPEZ-ROMERO, E.; MORÁN, N.; BENITO, A.; MARTÍNEZ-MORENO, J.; GOWLETT, J.; VICENT, J. M. (2007) Primeras intervenciones arqueológicas en el Abrigo de Buendía (Castejón, Cuenca). In: Rodríguez Ruza; Millán Martínez (Eds.) Actas de las 1. ${ }^{a}$ Jornadas de Arqueología en Castilla-La Mancha. Cuenca, p. 531-539.

UCATESCU,A.(2013) Visual culture and paideia: the triumph of the theatre revisiting the late antique mosaic of Noheda. Antiquite Tardive 21, p. 375-400.

VALERO TÉVAR, M.A. (1996) La Edad del Bronce en Cuenca. Ikalesken 1, p. 59-66.

(1999a) El Mundo Celtibérico en la Meseta Sur. Estado de la Cuestión. Ikalesken 3, p. 9-40.

(1999b) El Origen del Mundo Celtibérico en la Meseta Sur. Actas de I Encuentros sobre el Mundo Celtibérico, Guadalajara, p. 300-319.

(2009) La villa de Noheda: esplendor tardoimperial. Revista Memorias 15, p. 53-58.

(2010a) El yacimiento Arroyo del Egidillo, un asentamiento rural del siglo I d.C. (Villanueva de los Escuderos, Cuenca). In: Villar Díaz; Madrigal Belinchón (Coord.) Nuestro Patrimonio, Cuenca, p. 183-226.

(2010b) La villa romana de Noheda: Avance de los primeros resultados. Informes sobre Patrimonio 1, Toledo, p. 5-19.

(2011) Les images de ludi de la mosaïque de la villa romaine de Noheda (Villar De Domingo García - Cuenca). Nikephoros 24, p. 91-114.

(2012a) El yacimiento ibérico de Los Canónigos (Arcas del Villar-Cuenca) y su aportación al proceso de iberización de la Submeseta Sur. Madrid.

(2012b) La Protohistoria en el Área Nororiental de la Submeseta Sur. Studia Académica 17, p. 268-323.

(2013a) The late-antique villa at Noheda (Villar de Domingo García) near Cuenca and its mosaics. Journal of Roman Archaeology 26, p. 307-330. 
(2013b) El cambio de patrón poblacional en el territorium de Ercávica: avance sobre un proyecto de evolución del paisaje en la Alcarria. La romanización en la provincia de Guadalajara, Madrid, p. 235-299.

(2014) El triclinium de la villa tardoantigua de Noheda: edilicia y ornamentación. Actas del Convegno Internazionale La Villa Restaurata e i Nuovi Studi sull'Edilizia Residenziale Tardoantica.

(e.p.) Los mosaicos de la villa romana de Noheda (Villar de Domingo García-Cuenca). Contexto Arqueológico y análisis interpretativo. Cuenca.

VALERO TÉVAR, M. A., Merello, P.; Fernández Navajas, A, García-Diego, F.J., (2014a) Characterisation and evaluation of a thermo-hygrometric corrective action implemented in the Noheda's archaeological site (Noheda, Spain). Sensor 14, p. 1665- 1679.

VALERO TÉVAR, M. A. y Gómez Pallarés, J. (2013): El mimo del celoso adinerado: literatura y espectáculo en la villa de Noheda (Cuenca). Quaderni Urbitani di Cultura Classica 102, p. 87-106.

VALIENTE CÁNOVAS, S. (1974): Fragmento de cuenco campaniforme aparecido en Buendía (Cuenca), CuPAUAM 1, p. 133-138.

VARGAS JIMÉNEZ, J. M. y Romo Salas, A.M. (2002): E1 territorio de Osuna en la Antigüedad. Urso. Ala búsqueda de su pasado, Osuna, p. 147-186.

VEGAS DE WIGG, M. (1964): Clasificación tipológica preliminar de algunas formas de cerámica común romana. Barcelona.

VERA, D. (1992-1993): Schiavitù rurale e colonato nell'Italia imperiale. SASAA 6-7, p. 291-339.

VILLANUEVA ACUÑA, M. (1991): Problemas de la implantación agraria romana y la organización del territorio en la península ibérica en el Altoimperio. Espacio, Tiempo y Forma, Serie II, Ha Antigua, Tomo IV, p. 319-350.

VOLPE, G. (1996): Contadini, pastori e mercanti nell'Apulia tardoantica, Bari (Munera 6).

VOLPE, G. (2006): Stibadium e convivium in una villa tardoantica (Faragola-Ascoli-Satriano). In: Silvestrini, M., Spagnuolo Vigorita, T. e Volpe, G. (Eds.), Studi in onore di Francesco Grelle. Bari, p. 319-349.

ZARCO CUEVAS, M. (1575) Relaciones de pueblos del Obispado de Cuenca. Ed. revisada y preparada por Dimas Pérez Ramírez, Cuenca..

ZARZALEJOS PRIETO, Ma. M y Morillo Cerdán, A. (1994) Terra Sigillata procedente de la Cueva de Cavañiles (Huete, Cuenca). CuPAUAM 21, p. $159-182$.

VVAA, (1998): Guia de Castilla-La Mancha: Espacios naturales. Toledo. 